\title{
Generative housing: a shape grammar to design and to build social houses
}

\section{SIGRADI2018 TECHNOPOLITICAS \\ xxii congresso da sociedade iberoamericana de gráfica digital 22th conference of the iberoamerican society of digital graphics 07|08|09|novembro|2018 iau usp | são carlos | sp br}

\author{
Cristiana Griz \\ Universidade Federal de Pernambuco | Brazil | crisgriz@gmail.com \\ Thaciana Belarmino \\ Universidade Federal de Pernambuco | Brazil | thacianabelarminof@gmail.com \\ Julia Dutra \\ Universidade Federal de Pernambuco | Brazil | julialsdutra@hotmail.com \\ Jeane Karlla Barbosa \\ PopBim | Brazil | jeannekarlla@hotmail.com
}

\begin{abstract}
This paper shows the development of a system to generate customized small housing projects. The process of housing construction usually involves investment for the development of the project and for the management of the building process. In small housing, this investment is left aside for economic reasons. However, due to lack of it, the project may not be adequate and its construction can be even more costly. Aiming to contribute to this issue, this paper presents the creation of a generative design system, a shape grammar, that seeks to reinterpret the traditional design/construction process of housing.
\end{abstract}

Keywords: Generative design; shape grammar; housing; visual proggraming.

\section{INTRODUÇÃO}

Esse artigo apresenta o desenvolvimento de uma investigação feita com parceria entre o Departamento de Expressão Gráfica da UFPE e a PopBim - startup incubada no Porto Digital, Recife. O foco gira em torno da questão de projetos e construção de qualidade para habitação de interesse social.

O processo de construção de habitações, independente do seu tamanho, geralmente envolve investimento para o desenvolvimento do projeto e para o gerenciamento e execução da obra. Em se tratando de habitação de pequeno porte, esse investimento é, muitas vezes, deixado de lado por razões econômicas. O curioso é que, justamente pela falta dele, o projeto pode não ser adequado e sua construção pode resultar ainda mais onerosa. Assim, grande parte das pessoas que conseguem adquirir um terreno em loteamentos de pequeno e médio porte começam a construir suas moradias sem planejamento, sem o auxílio de um técnico que possa desenvolver um projeto adequado e, portanto, sem oferecer qualidade à moradia e, ao mesmo tempo, sem possibilitar que a construção seja eficiente, tanto do ponto de vista técnico, quanto econômico.

O que poucas pessoas sabem é que o Programa Minha Casa Minha Vida (MCMV) ${ }^{1}$, além de financiar moradias já construídas por terceiros, também destina parte dos seus

${ }^{1}$ Implementado em março de 2009, o Programa Minha Casa Minha Vida foi criado com o objetivo de possibilitar que a população com rendimentos de até 10 salários mínimos pudesse ter acesso à moradia (RANGEL, 2011). financiamentos para a construção de habitações para aqueles que adquirem um terreno. A principal exigência é ter um projeto arquitetônico aprovado na prefeitura local objeto que a maioria dessa camada da população não tem acesso, fazendo com que esse tipo de financiamento fique ocioso.

Visando contribuir com essa questão, a PopBim buscou parceria com a UFPE para, juntos, desenvolverem um aplicativo que atende não apenas à demanda dessa camada da população, mas também faz mediação entre esses e fornecedores da construção civil local. O software irá se desenvolver baseado nos princípios do design generativo, mais especificamente a gramática da forma, que servirá de base para a geração customizada de projetos de habitação.

Segundo Fischer e Herr (2001), design generativo é uma metodologia de projeto que se diferencia de outras abordagens projetuais, pois durante o processo de projeto o projetista não interage de maneira direta com produto que está sendo projetado, e sim, através de um sistema generativo. Para Celani (2011), um sistema generativo é um método indireto de projeto, no qual o projetista não se preocupa apenas com a solução de um problema em particular em um contexto específico, mas em criar um projeto genérico, que possibilite resolver problemas semelhantes em contextos diferentes. 
Um dos sistemas generativos de projeto $^{2}$ é a gramática da forma. Criada por Stiny e Gips (1972), ela consiste em um sistema de geração de formas baseado em regras que, aplicadas passo a passo, são capazes de gerar uma linguagem de projeto (Eloy, 2012). Nesse sentido, a questão da customização é atendida com a aplicação desse formalismo, na medida em que ele possibilita a criação de projetos a partir de uma forma inicial por meio da aplicação recursiva de regras compositivas e, dentre outros fatores, torna possível conseguir a viabilidade econômica e construtiva em projetos de HIS.

A aplicação da gramática da forma como método para gerar habitações customizadas já foi introduzido por vários autores (Duarte, 2007; Mussi, 2014; Eloy, 2012; Mayer, 2012), evidenciando, assim, a mudança de paradigma no processo de projeto quando se deseja alcançar certo nível de personalização. Isso acontece, pois, este formalismo é utilizado como estratégia definidora das regras de concepção do projeto arquitetônico personalizado, como facilitadora da incorporação do usuário na concepção projetual, sendo, assim, promotora da personalização da unidade habitacional em série.

Tendo esta problemática como pano de fundo, a presente investigação busca reinterpretar o tradicional processo de projeto/construção de habitações de pequeno porte. Isso é feito através do desenvolvimento de um sistema que vai facilitar o acesso a um projeto arquitetônico por essa camada da população, com a geração de projetos customizados de habitação de pequeno porte, de maneira otimizada.

Para isso, a gramática proposta precisa ser desenvolvida em três estágios:

1. O estágio 1 diz respeito à organização espacial da habitação. Aqui, são definidas regras que dizem respeito à funcionalidade e resultam em diversas maneiras de organizar espacialmente os ambientes da habitação, de acordo com dados de entrada específicos, como o número de ambientes, o tipo de interação entre eles (se mais restritivo ou mais interativo, por exemplo).

2. O estágio 2 trata da volumetria do projeto. É desenvolvido necessariamente a partir da solução espacial selecionada no estágio anterior e guiado por outro conjunto de dados de entrada - altura do pédireito, tipo de coberta, etc.

3. O estágio 3 é responsável pela definição dos elementos construtivos da habitação. Nesta fase são definidas as regras que irão decompor a volumetria definida no estágio anterior nos elementos construtivos da habitação - paredes, pisos, tetos, cobertas, esquadrias, etc.

Cada estágio é desenvolvido em duas etapas: a parte analógica e a parte digital. A primeira mostra o processo de inferência de regras e o teste de aplicação dessas regras, através da derivação feita manualmente, regra por regra. A segunda faz uso de tecnologias digitais para

${ }^{2}$ Além dos fractais, do algoritmo genético, do design paramétrico, dentre outros. implementar as regras de maneira que as soluções geradas pela gramática sejam obtidas de maneira automatizada e otimizada.

Este artigo apresenta a parte analógica do estágio 1, onde é descrito o desenvolvimento da parte da gramática responsável pela distribuição funcional e organização espacial da habitação. Para o estudo de caso, foi feita uma parceria com empreendedores de um loteamento localizado no município de Itapissuma (PE), que conta com terrenos com área média de $200 \mathrm{~m}^{2}$.

\section{ELABORANDO A GRAMÁTICA}

Como comentado, a gramática da forma vem sendo explorada, ao longo do tempo, em diversas aplicações para resolução de problemas projetuais, investigando como gerar projetos a partir de uma forma inicial, por meio de sucessivas aplicações de regras de forma (Duarte, 2007; Knight, 2000; Celani et al, 2006).

As gramáticas podem ser classificadas de acordo com: (a) a maneira como as regras são inferidas; (b) a lógica de aplicação das regras. A primeira maneira define as duas principais classificações descritas por Duarte (2007) - gramáticas analíticas e gramáticas originais. As analíticas são concebidas como ferramenta de análise de um grupo de projetos - o corpus, que formam uma única linguagem que os represente. Essa representação é feita por meio de regras que são inferidas a partir da análise dos próprios projeto que formam o corpus. Já as originais são concebidas para gerar novos projetos e as regras, neste caso, não são necessariamente criadas a partir da análise de projetos, e sim, baseadas em requisitos préestabelecidos e descritos em textos, normas, etc.

Em relação à lógica de aplicação as gramáticas podem ser de vários tipos (Knigth, 1999). As principais são as básicas (onde são aplicadas apenas regras de adição), as não determinísticas (são aplicadas regras da gramática e mostradas várias derivações que a ordem de aplicação das regras gera), as sequenciais (as regras são aplicadas numa ordem pré-definida), e as irrestritas (qualquer tipo de regra é aplicada em qualquer ordem).

Além disso, qualquer um desses tipos pode ser paramétrico. Uma gramática paramétrica é usada para codificar ordenadamente uma gama mais ampla de variações formais para a mesma regra. Ou seja, cada regra consiste em uma série de regras que podem codificar variados atributos da forma, de maneira que uma maior variedade de parâmetros relacionados à forma podem ser combinadas (Figura 2).

O primeiro estágio da gramática ora desenvolvida é, em parte analítica, outra parte, original, é do tipo sequencial e, por fim, será paramétrica. Como é descrito a seguir

\section{A GRAMÁTICA DA HABITAÇÃO GENERATIVA}

Este estágio de desenvolvimento da gramática tem foco na geração automatizada de soluções que apresentem variadas organizações espaciais para a habitação. O terreno padrão do loteamento selecionado para estudo de caso tem $10 \mathrm{~m} \times 20 \mathrm{~m}$, com frente ora para o Leste, ora para o Oeste. 
O processo de inferência de regras contou com a análise tanto de projetos de habitação de interesse social de reconhecido valor técnico (Aravena; lacobelli, 2012; Mayer, 2012), quanto de pesquisa e recomendações sobre projetos de habitação social (Kowaltowski et al, 2015)

Dentre os projetos analisados, dois foram elaborados pelo escritório de arquitetura chileno, Elemental: (a) o Quinta Monroy e, (b) a Habitação Villaverde. Em ambos os casos, Aravena toma como partido a noção de arquitetura incremental - apenas um embrião inicial com áreas mínimas é entregue, ficando livre para cada usuário expandir de acordo com sua necessidade. Assim, estes projetos conseguem manter o equilíbrio entre baixos custos e personalização (Aravena; lacobelli, 2012).

Outra referência que serviu de base para 0 desenvolvimento das regras da gramática foi o trabalho desenvolvido por Mayer (2012). A autora argumenta que a padronização dos projetos é consequência da busca da redução de custos e do encurtamento do tempo de execução. Para combater a padronização, ela cria uma gramática da forma baseada num sistema modular adimensional que toma como partido as relações espaciais (relações de adjacência, circulação, aberturas, etc.). Mayer propõe, também, a abstração das restrições dimensionais, e trabalha com modelos espaciais topológicos extraídos do corpus estudado. Cria, assim, modelos matriciais a partir do qual é possível a geração de alternativas, criando, portanto, um extenso leque de opções a partir de um número limitado de regras.

Nesse sentido, alguns dos princípios apresentados por esses e por outros trabalhos de referência no campo da arquitetura generativa para habitações (Duarte, 2007; Mussi, 2014; Eloy, 2012) serviram como base para a criação das regras da gramática proposta, como é visto a seguir.

\section{AS REGRAS DA GRAMÁTICA}

A geração da habitação segue basicamente quatro conjuntos de regras, que devem ser aplicadas exatamente na ordem apresenta - daí o caráter sequencial da gramática. São (a) as regras de implantação; (b) as regras de divisão de ambientes; (c) as regras de atribuição funcional e, (d) as regras de atribuição dimensional.

O primeiro grupo de regras define as opções de implantação da habitação no terreno. Para tanto, são levados em conta parâmetros relativos à orientação do terreno, às normas de afastamento e à área da habitação (Figuras 1 e 2). Como comentado, o loteamento apresenta terrenos voltados para o Leste ou para o Oeste. Essa é o primeiro parâmetro a ser definido, com a escolha entre aplicar a regra $\mathrm{L} 1$ e ou a regra $\mathrm{L} 2$.

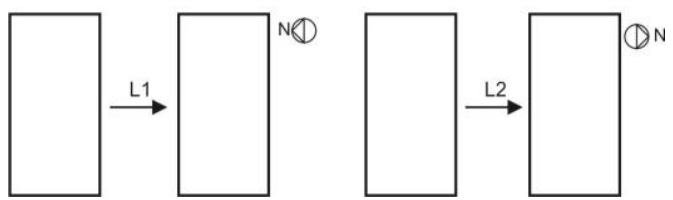

Figura 1: Regras para atribuir a orientação do lote. Fonte: autores.
Tendo definido qual a orientação do terreno, aplica-se a regra L3 - uma única regra referente a afastamentos (Figura 2). Entretanto, por ser paramétrica, é capaz de gerar uma grande variedade formal, ao mesmo tempo em que atende às restrições descritas nas condições associadas a ela. As primeiras restrições, descritas nas condições gerais, são referentes às leis de afastamento definidas pela prefeitura local para esse tipo de loteamento e que geram uma implantação de edificação solta no terreno. Porém, é possível que a edificação cole no limite do terreno, caso atenda as condições particulares 1. Por fim, as condições particulares 2 definem afastamentos distintos dos definidos nas condições gerais. Esses objetivam uma maior flexibilidade para a locação da edificação, de maneira que esta possa proporcionar maior conforto em termos de ventilação e/ou insolação, ou mesmo para possibilitar a inclusão de garagens ou outros itens programáticos.

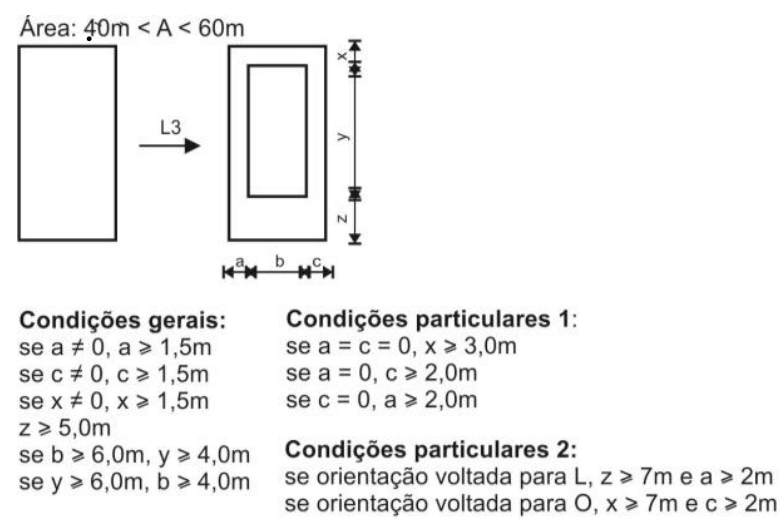

Figura 2: Regra paramétrica par definir o polígono que representa o perímetro esquemático da habitação. Fonte: autores.

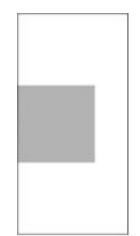

Colado lat. esq.

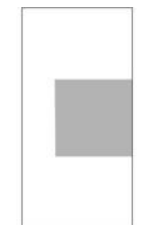

Colado

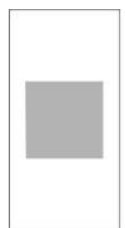

Solto no

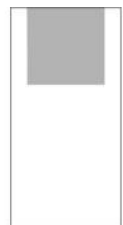

Colado no fundo

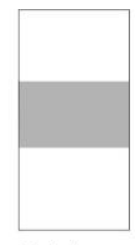

Colado nas laterais
Figura 3: Exemplos de implantação esquemática da habitação no terreno, resultado da aplicação da regra paramétrica L3. Fonte: autores.

Vale ressaltar que, para que a implantação resultante "provisória"3 da habitação seja definida é preciso que, a priori, o morador já tenha escolhido o programa arquitetônico (número de ambientes) e, consequentemente, a área média da habitação (Tabelas 1 a 8). Com esses dados é possível obter cinco possibilidades esquemáticas de implantação (Figura 3), que podem variar posteriormente, de acordo com as regras de atribuição dimensional.

\footnotetext{
${ }^{3} \mathrm{~A}$ implantação final da habitação é definida apenas após a aplicação das regras de atribuição dimensional.
} 
Tabela 1: Área $\left(\mathrm{em} \mathrm{m}^{2}\right.$ ) e programa arquitetônico para habitação com seis ambientes.

\begin{tabular}{llll}
\hline Ambiente & Min & Med & Max \\
\hline ESTAR & 7 & 8 & 9 \\
\hline JANTAR & 7 & 8 & 9 \\
\hline COZINHA & 6 & 6 & 6 \\
\hline BWC & 2 & 2 & 2 \\
\hline QUARTO 1 & 9 & 10 & 11 \\
\hline QUARTO 2 & 9 & 10 & 11 \\
\hline TOTAL & 40 & 44 & 48 \\
\hline
\end{tabular}

Tabela 2: Área $\left(e m \mathrm{~m}^{2}\right)$ e programa arquitetônico para habitação com sete ambientes com opção de duas cozinhas e dois quartos.

\begin{tabular}{llll}
\hline Ambiente & Min & Med & Max \\
\hline ESTAR & 8 & 9 & 10 \\
\hline JANTAR & 8 & 9 & 10 \\
\hline COZINHA & 4 & 4 & 4 \\
\hline COZINHA & 4 & 4 & 4 \\
\hline BWC & 2 & 2 & 2 \\
\hline QUARTO 1 & 9 & 10 & 11 \\
\hline QUARTO 2 & 9 & 10 & 11 \\
\hline TOTAL & 44 & 48 & 52
\end{tabular}

Tabela 3: Área (em $\mathrm{m}^{2}$ ) e programa arquitetônico para habitação com sete ambientes com opção de dois banheiros e dois quartos.

\begin{tabular}{llll}
\hline Ambiente & Min & Med & Max \\
\hline ESTAR & 8 & 9 & 10 \\
\hline JANTAR & 8 & 9 & 10 \\
\hline COZINHA & 7 & 7 & 7 \\
\hline BWC & 2 & 2 & 2 \\
\hline BWC & 2 & 2 & 2 \\
\hline QUARTO 1 & 9 & 10 & 11 \\
\hline QUARTO 2 & 9 & 10 & 11 \\
\hline TOTAL & 45 & 49 & 53
\end{tabular}

Tabela 4: Área $\left(e m \mathrm{~m}^{2}\right)$ e programa arquitetônico para habitação com sete ambientes com opção de três quartos.

\begin{tabular}{llll}
\hline Ambiente & Min & Med & Max \\
\hline ESTAR & 8 & 9 & 10 \\
\hline JANTAR & 8 & 9 & 10 \\
\hline COZINHA & 7 & 7 & 7 \\
\hline BWC & 2 & 2 & 2 \\
\hline QUARTO 1 & 9 & 10 & 11 \\
\hline QUARTO 2 & 9 & 10 & 11 \\
\hline QUARTO 3 & 9 & 10 & 11 \\
\hline TOTAL & 52 & 57 & 62
\end{tabular}

Tabela 5: Área (em $\mathrm{m}^{2}$ ) e programa arquitetônico para habitação com oito ambientes com opção de duas cozinhas e três quartos.

\begin{tabular}{llll}
\hline Ambiente & Min & Med & Max \\
\hline ESTAR & 9 & 10 & 11 \\
\hline JANTAR & 9 & 10 & 11 \\
\hline COZINHA & 4 & 4 & 4 \\
\hline COZINHA & 4 & 4 & 4 \\
\hline BWC & 2 & 2 & 2 \\
\hline QUARTO 1 & 9 & 10 & 11 \\
\hline QUARTO 2 & 9 & 10 & 11 \\
\hline QUARTO 3 & 9 & 10 & 11 \\
\hline TOTAL & 55 & 60 & 65
\end{tabular}

Tabela 6: Área $\left(\mathrm{em} \mathrm{m}^{2}\right.$ ) e programa arquitetônico para habitação com oito ambientes com opção de dois banheiros e três quartos.

\begin{tabular}{llll}
\hline Ambiente & Min & Med & Max \\
\hline ESTAR & 9 & 10 & 11 \\
\hline JANTAR & 9 & 10 & 11 \\
\hline COZINHA & 8 & 8 & 8 \\
\hline BWC & 2 & 2 & 2 \\
\hline BWC & 2 & 2 & 2 \\
\hline QUARTO 1 & 9 & 10 & 11 \\
\hline QUARTO 2 & 9 & 10 & 11 \\
\hline QUARTO 3 & 9 & 10 & 11 \\
\hline TOTAL & 57 & 62 & 67
\end{tabular}

Tabela 7: Área $\left(\mathrm{em} \mathrm{m}^{2}\right.$ ) e programa arquitetônico para habitação com oito ambientes com opção de duas cozinhas, dois banheiros e dois quartos.

\begin{tabular}{llll}
\hline Ambiente & Min & Med & Max \\
\hline ESTAR & 10 & 11 & 12 \\
\hline JANTAR & 10 & 11 & 12 \\
\hline COZINHA & 5 & 5 & 5 \\
\hline COZINHA & 5 & 5 & 5 \\
\hline BWC & 2 & 2 & 2 \\
\hline BWC & 2 & 2 & 2 \\
\hline QUARTO 1 & 11 & 12 & 12 \\
\hline QUARTO 2 & 11 & 12 & 12 \\
\hline TOTAL & 56 & 60 & 62
\end{tabular}

Tabela 8: Área $\left(e m \mathrm{~m}^{2}\right.$ ) e programa arquitetônico para habitação com nove ambientes.

\begin{tabular}{llll}
\hline Ambiente & Min & Med & Max \\
\hline ESTAR & 11 & 12 & 13 \\
\hline JANTAR & 11 & 12 & 13 \\
\hline COZINHA & 6 & 6 & 6 \\
\hline COZINHA & 6 & 6 & 6 \\
\hline BWC & 2 & 2 & 2 \\
\hline BWC & 2 & 2 & 2 \\
\hline QUARTO 1 & 10 & 11 & 12 \\
\hline QUARTO 2 & 10 & 11 & 12 \\
\hline QUARTO 3 & 10 & 11 & 12 \\
\hline TOTAL & 68 & 73 & 78
\end{tabular}

A partir da escolha de uma das implantações esquemáticas é hora de aplicar o segundo conjunto de regras - as que definem a divisão do polígono resultante da implantação em ambientes. Tendo em vista a camada social que forma o público-alvo de compradores deste loteamento, as habitações podem variar de $40 \mathrm{~m}^{2}$ a $80 \mathrm{~m}^{2}$, apresentando de seis a nove ambientes, com possibilidade de combinação variada de funções. Como mostra as Tabelas 1 a 8 , com exceção da habitação com seis ambientes, o morador pode escolher o programa funcional da sua moradia, com opções de dois ou três dormitórios, um ou dois banheiros ou com cozinha com dimensão mínima ou mais ampla. Seguindo esses critérios e a escolha do cliente, o polígono resultante da implantação pode ser dividido, então, em seis a nove polígonos menores, cujas regras de subdivisão variam de acordo com o número de ambientes, a dimensão do polígono resultante da implantação e, em alguns casos, com a orientação do terreno (Figura 4). 

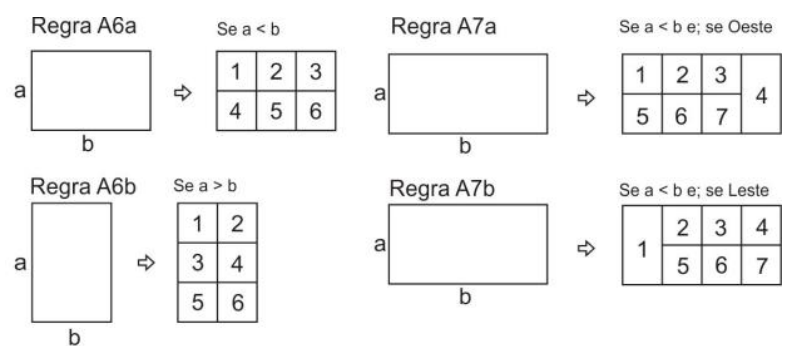

Regra A7c
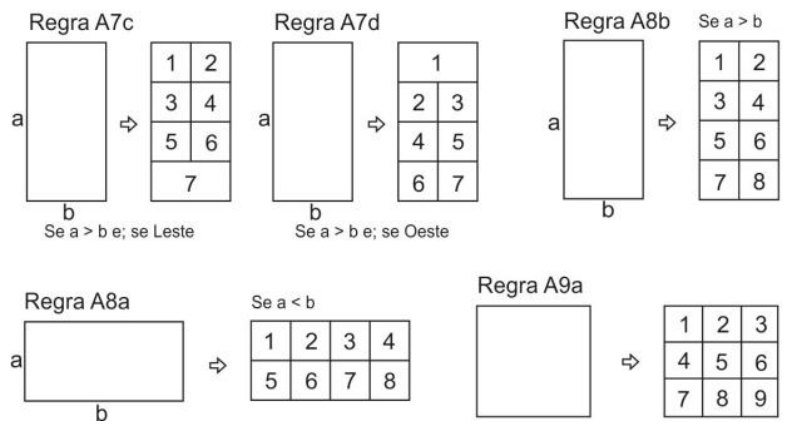

Figura 4: Regras de divisão do polígono resultante da implantação no número de ambientes. Fonte: autores.

Tendo definida a subdivisão, o próximo passo é atribuir função a cada um desses ambientes- tarefa feita com a aplicação das regras apresentadas na Figura 5 . Distintamente de Mayer (2012), a primeira função que deve ser atribuída é a cozinha. Em seguida vem a locação das salas, que, conforme análise do corpus, está adjacente à sala em $100 \%$ dos casos. A locação dos quartos e dos banheiros vem, respectivamente, logo em seguida.

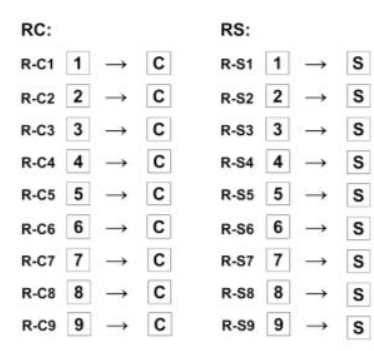

RC: Regra de alocação da cozinha $R Q$ : Regra de alocação do quarto

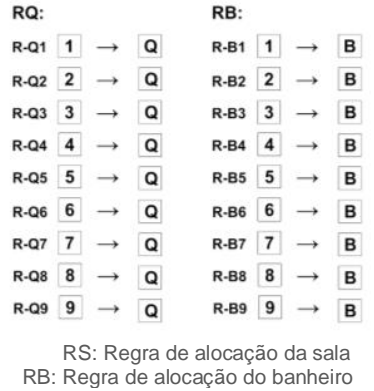

RB: Regra de alocação do banheiro
Figura 5: Regras de atribuição funcional. Fonte: autores.

Vale destacar que a locação das funções depende não apenas do número de ambientes total da habitação, mas também (e como em todo projeto de arquitetura) da orientação do terreno. Nesse sentido, para cada modelo de subdivisão de ambientes são definidas as posições possíveis que a cozinha, sala e quartos podem ser atribuídas (Figura 6). Essa definição facilitará a implementação da gramática, uma vez que cada orientação apresenta um número limitado e específico de regras de atribuição de função que pode ser aplicada.

Tomando-se como exemplo um terreno cuja frente é voltada para o Oeste, com oito ambientes e cujo polígono resultante da implantação tem largura menor que a profundidade. Para tal opção, a locação da cozinha só pode ser feita nos ambientes número 3,5 ou 7 (Figura 6). Ou seja, para esse exemplo, só podem ser aplicadas as regras de atribuição funcional RC3, RC5 ou RC7 (Figura 5). Já a locação da sala, além de ter que estar adjacente à cozinha, só pode ser nos ambientes número 1, 2, 4, 6 ou 8 (regras de atribuição funcional RS1, RS2, RS4, RS6 ou RS8, respectivamente).

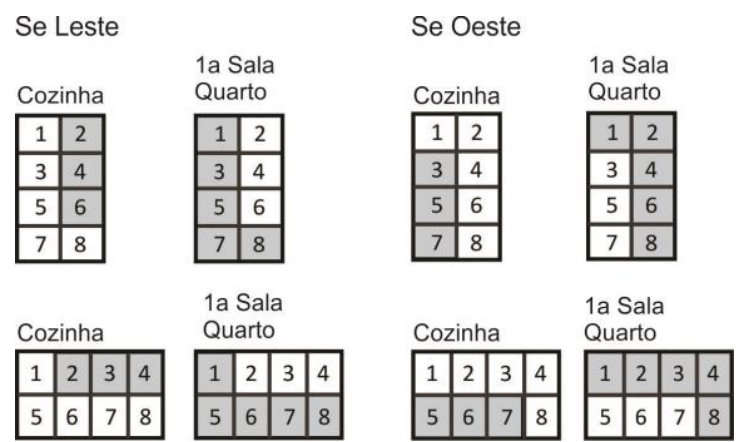

Figura 6: Possibilidades de locação para cozinha, sala e quartos em habitações de oito ambientes. Fonte: autores.

O quarto e último grupo de regras que formam esse estágio da gramática são responsáveis por definir as dimensões de cada um dos ambientes, sem alterar a relação de adjacência pré-definida. Apesar dessa etapa ainda estar em desenvolvimento, já foi definido que as dimensões dos ambientes tomarão por base as áreas discriminadas nas Tabelas 1 a 8 - o que pode resultar numa infinidade de formatos de habitação, mesmo que, inicialmente, tenha-se como base apenas um esquema de subdivisão de ambientes, como é apresentado a seguir.

\section{GERANDO A ORGANIZAÇ̃̃O ESPACIAL DAS HABITAÇÕES}

Para exemplificar a aplicação passo a passo das regras é apresentada a derivação de uma habitação com oito ambientes, onde o morador optou por três dormitórios, sendo um, uma suíte. O terreno é voltado para o Leste (aplicação da regra L2) e, como resultado da regra paramétrica de afastamentos (regra L3), o polígono resultante da implantação fica solto no lote. Esse polígono apresenta uma maior dimensão na profundidade do que na largura, fato que direciona a aplicação da regra A8a para subdivisão dos ambientes.

Como o lote é voltado para o Leste e o polígono é mais profundo que largo, as posições possíveis para locar a cozinha são nos números 2, 4 ou 6 (como indicado na Figura 6). O segundo ambiente a ser atribuído é a sala. Para esta orientação, a sala só é possível ser localizada nos números $1,2,5,7$ ou 8 . No entanto, caso a cozinha tenha sido locada na posição 2 , a sala só poderá ficar nos 1 ou 3 , já que outra restrição é que a sala tem que ser adjacente à cozinha. Já se a opção de posicionamento da cozinha tiver sido no número 6 , a sala pode ser locada nos $3,5,7$ ou 8 , pois em todas essas posições é possível ter a adjacência com a cozinha.

E assim segue-se a sequência de atribuição do segundo ambiente referente à sala (estar e/ou jantar), dos quartos e dos banheiros. Não esquecendo que a escolha da localização de um ambiente influencia diretamente a localização do próximo. Como resultado, temos uma espécie de "árvore" que mostra as possíveis derivações que geram12 organizações espaciais esquemáticas de habitações com oito ambientes (com dois dormitórios e uma suíte), cujo lote é voltado para o Leste (Figura 7). 


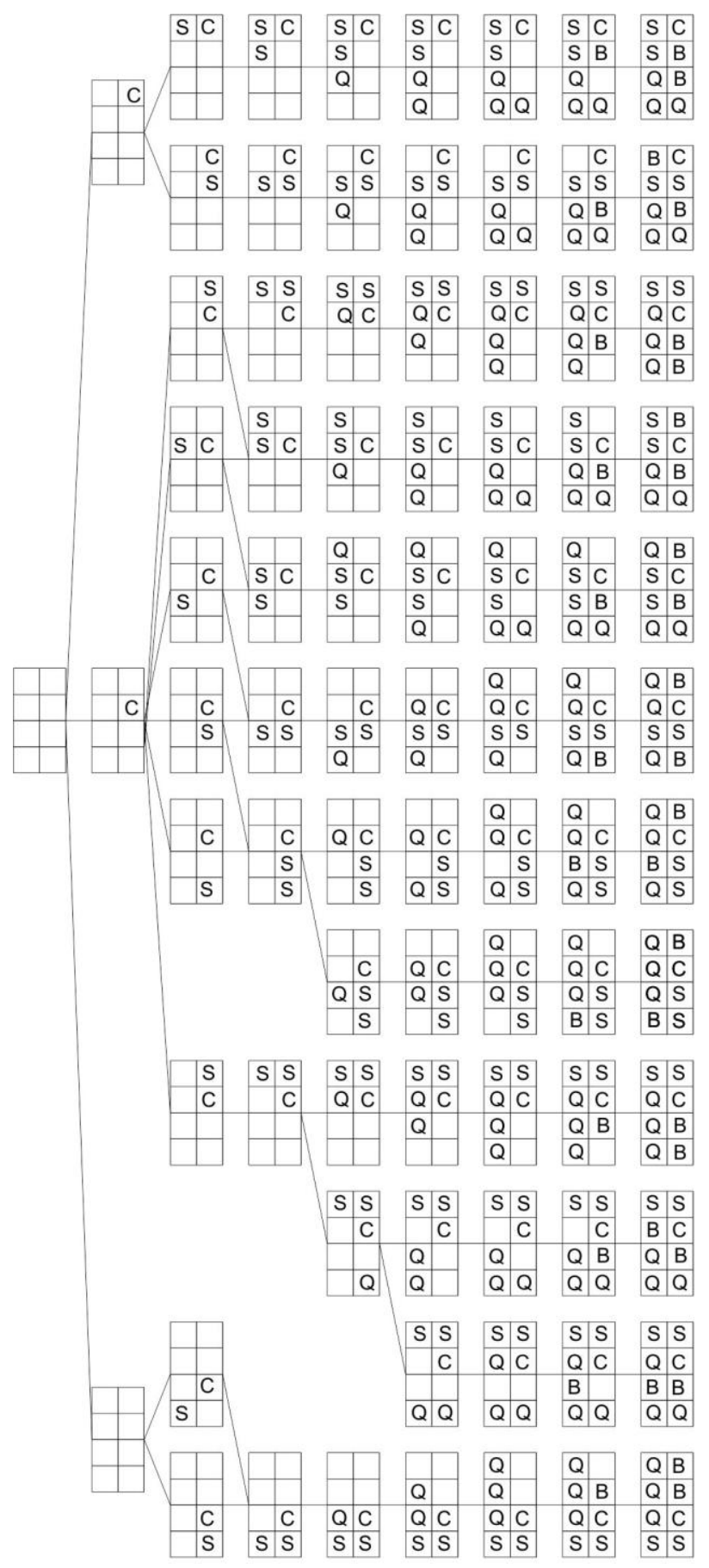

Figura 7: Árvore de derivações que geram 12 organizações espaciais esquemáticas de habitações com oito ambientes (com dois dormitórios e uma suíte), cujo lote é voltado para o Leste. Fonte: autores.

Por fim, uma das organizações espaciais esquemáticas é escolhida pelo cliente para que sejam aplicadas as regras paramétricas que definem as dimensões dos ambientes (ainda em elaboração). Com a aplicação dessas regras sabe-se que é possível que uma única organização espacial esquemática seja capaz de gerar um grande número de plantas distintas, mas que guardam as mesmas relações de adjacência definidas na distribuição espacial esquemática (Figura 8).

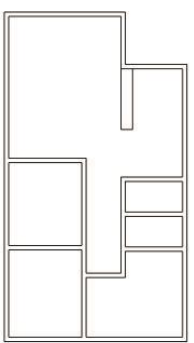

Planta 1

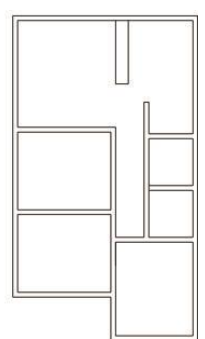

Planta 2
Figura 8: Exemplos de plantas geradas a partir de uma mesma organização espacial esquemática. Fonte: autores.

\section{CONSIDERAÇÕES FINAIS}

O desenvolvimento de uma gramática que busca reinterpretar o tradicional processo de projeto/construção de habitações de médio e pequeno porte é um processo longo. Esta etapa teve foco apenas na primeira fase (a analógica) do estágio 1 , referente à definição da organização espacial da habitação, sempre buscando otimizar e automatizar as soluções espaciais possíveis. No entanto, mesmo sem ter finalizado a implementação das regras, é possível perceber que elas permitem a geração de uma infinidade de organizações espaciais esquemáticas que, por sua vez, resultarão em variados tipos de plantas customizadas pelos clientes.

Sabendo que o sucesso de todo tipo de produto, neste caso, o projeto/construção de habitação a preço acessível, está na compatibilização entre a expertise do técnico e as demandas personalizadas do cliente, o design generativo entra como um instrumento metodológico que permite essa confluência de saberes. Esta união, por sua vez, é cada vez mais possível com o uso de tecnologias digitais capazes de proporcionar a participação desses dois atores nas definições do projeto de maneira mais eficaz. Isso é conseguido com a implementação da gramática ora desenvolvida, que fomentará, também, a discussão sobre a reinterpretação do processo de projeto/construção de habitações de pequeno porte.

\section{AGRADECIMENTOS}

Os autores agradecem a professora Leticia Mendes e ao aluno Jorge Alcântara Filho pela consultoria técnica que rendeu bons encaminhamentos para o desenvolvimento da gramática da forma.

\section{REFERÊNCIAS}

Aravena, A.;lacobelli, A. (2012). Elemental: manual de vivienda incremental y diseño participativo. Ostfildern: HatjeCantz.

Celani, G.; Cypriano, D.; Godoi, G.; Vaz, C. E. V. (2006) A gramática da forma como metodologia de análise e síntese em arquitetura. Conexão - comunicação e cultura/Universidade de Caxias do Sul, Caxias do Sul, v. 5, n. 10 , p. 180-197.

Celani, C. (2011). AlgorithmicSustainable Design. Vitruvius, v.116. Disponível http://www.vitruvius.com.br/revistas/read/resenhasonline/10. 116/3995

Duarte, J. P. (2007). Personalizar a habitação em série: Uma Gramática Discursiva para as Casas da Malagueira do Siza. Lisboa: Ed. Fundação Calouste Gulbenkian. 
Eloy, S. (2012) A transformationgrammar-basedmethodology for housingrehabilitation: meeting contemporaryfunctionaland ICT requirements. (PhD). Universidade Técnica de Lisboa, Lisboa.

Fischer, T.; Herr, C. M. (2001). TeachingGenerative Design. In 4th InternationalGenerativeArtConference, Generative Design. Milão. Disponível em: <http://www.generativeart.com>. Acesso em: 14 abril 2015.

Knigth, T. (1999). Shapegramars: SixTypes.Environmentand Planning B: UrbanAnalyticsand City Science. Fev, 1999.

Knight, T. (2000). ShapeGrammars in educationandpractice: historyand prospects. InternationalJournalof Design Computing, v. 2 . Disponível em < http://www.mit.edu/ tknight/IJDC/ >. Acesso em: 24 set. 2015.

kowaltowski, K.; Granja, D..; Moreira, D.;Pina, S.; Oliva, C.; Castro, M.(2015). The BrazilianHousingprogram 'Minha Casa Minha Vida' - A SystematicLiteratureReview In Journalofthe Korean housingassociation, v. 26, p. 35-42.

Mayer, R. (2012). A gramática da habitação mínima. Análise do Projeto Arquitetônico de Interesse Social em Porto Alegre e
Região Metropolitana. (Tese de Doutorado em Arquitetura). Universidade Federal do Rio Grande do Sul, Porto Alegre.

Mussi, A. Q. (2014). Os Padrões de Ampliação Espontânea de Interesse Socialem Porto Alegre, RS, e Região Metropolitana: Uma Proposta de Aplicação da Gramática da Forma e

Sintaxe Espacial (Tese de Doutorado em Arquitetura). Universidade Federal do Rio Grande do Sul.

RANGEL, J. (2011). O Programa "Minha cada minha vida" e seus desdobramentos no local: um estudo da pequena cidade de Ponta de Pedras, Pará. (Dissertação de Mestrado em Planejamento Urbano e Regional). Universidade do Vale do Paraíba, São José dos Campos.

Stiny,

$$
\text { G.; }
$$$$
\text { Gips, }
$$$$
\text { J. }
$$

(1972) Shapegrammarsandthegenerativespecificationofpaintingand sculpture In 7th IfipCongress. Amsterdam. Disponível em: <http://www.shapegrammar.org/ifip/ifip1.html>. Acesso em: 05 nov. 2014. 